\title{
De Y se llamaban a Mahmud y Ayaz a Voces en el silencio: del poema al texto teatral
}

\author{
José Manuel Lucía Megías \\ Universidad Complutense de Madrid
}

El 19 de julio del 2005 fueron ejecutados en la ciudad iraní de Mashad los jóvenes árabes Mahmud Asgari y Ayaz Marhoni. En el informe de Amnistía Internacional fechado el 27 de junio de 2007, con el título "Irán, el último verdugo de menores", se recoge la noticia de este asesinato con las siguientes palabras:

Ayaz Marhoni y Mahmud Asgari, árabes iraníes, fueron ahorcados en público en una plaza de Mashad el 19 de julio de 2005. Amnistía Internacional cree que Mahmud Asgari tenía 15 o 16 ańos y Ayaz Marhoni 16 o 17 cuando cometieron el delito por el que fueron ejecutados. Les dieron 228 latigazos antes de la ejecución. La verdadera naturaleza del presunto delito sigue siendo objeto de controversias. Las fotografías de los dos muchachos cuando eran conducidos al lugar de la ejecución y en el momento de ser ejecutados se publicaron en todo el mundo y suscitaron la condena internacional. En una foto aparecen llorando mientras unos periodistas los entrevistan camino de la horca. En otra se les ve con los ojos vendados y de pie en un camión, sobre el que se alza la grúa que va a servir de horca, mientras a sus espaldas dos hombres enmascarados les colocan una soga alrededor del cuello. En otra aparecen colgados de la grúa. Unos testigos seńalaron que tardaron unos 20 minutos en morir, y al parecer una gran multitud presenció la ejecución. En el informe oficial, del que se hicieron eco el diario Quds y el sito web de la Agencia de Noticias de los Estudiantes Iraníes, se afirma que habían sido declarados culpables de "actos homosexuales bajo coacción", expresión con la que se hacía referencia a la violación de un chico de 13 años. Habían sido declarados culpables también de consumo de alcohol, robo y desórdenes públicos, delitos por los que les impusieron penas de flagelación. Quds publicó un relato detallado de 
la violación del chico a punta de cuchillo, basado al parecer en declaraciones realizadas por su padre. Según los informes, Mahmud Asgari había sido declarado culpable también de extorsión y agresión con un cuchillo, y Ayaz Marhoni, de causar lesiones de forma deliberada. Por estos delitos les impusieron multas y penas de cárcel. Fueron ejecutados antes de que cumplieran las penas de cárcel. Después de las ejecuciones, algunas fuentes han señalado que Ayaz Marhoni y Mahmud Asgari eran pareja y que fueron ejecutados por realizar actos sexuales de mutuo acuerdo entre ellos y, tal vez, con el chico de 13 años. Otras fuentes descartan esta versión.

Homan, colectivo iraní de derechos de los homosexuales, afirma que el gobierno iraní ha condenado a muerte desde la llegada de la Revolución en 1979 alrededor de 4000 homosexuales. Irán es el segundo país del mundo en ejecuciones, superado tan solo por China, según fuentes de Amnistía Internacional. Nueve países árabes aún tienen la homosexualidad como una de las causas de pena de muerte.

El conflicto del uranio enriquecido y la posibilidad de crear bombas atómicas, la posición estratégica de Irán en una de las geografías más inestables del mundo y su petróleo — que le ha llevado a firmar cuantiosos contratos y acuerdos con países como Venezuela y Brasil- han hecho que el tema de los derechos humanos en Irán haya pasado a un segundo plano. En Irán y en tantos otros países árabes, aliados de los intereses occidentales en la zona como Arabia Saudí, mueren muchos jóvenes que cometen el delito de amarse. Y lo hacen colgados de unas grúas que causan deshonor a sus familias y silencio en nuestras conciencias.

En noviembre de 2008, más de tres años después del asesinato de Mahmud y Ayaz, me asaltaron en el ordenador las tres fotografías que dieron la vuelta al mundo, donde se les podía ver llorando mientras eran entrevistados antes de su asesinato, su llegada vendados a donde iban a morir y la serenidad de sus rostros en el momento en que los asesinos, escondidas sus caras bajo cobardes pañuelos, les ajustaban las sogas asesinas. Tres fotos que se habían multiplicado en los periódicos y noticieros de todo el mundo, como recordaba el informe de Amnistía Internacional, y que solo ahora se volvían una imagen real, única en mi retina.

De la indignación que me produjeron estas fotos, el conocer la forma y la causa del asesinato de Mahmud y Ayaz, dan buena cuenta las primeras páginas del cuaderno donde comencé a escribir mis impresiones. Seguí indagando en Internet y no dejé de encontrar otros ajusticiamientos en la plaza pública por ahorcamiento... y la multitud allí congregada, multiplicando el asesinato con sus cámaras fotográficas digitales. La última tecnología al servicio de una práctica de antiguos tiempos, de tiempos remotos que creíamos ya superados. 

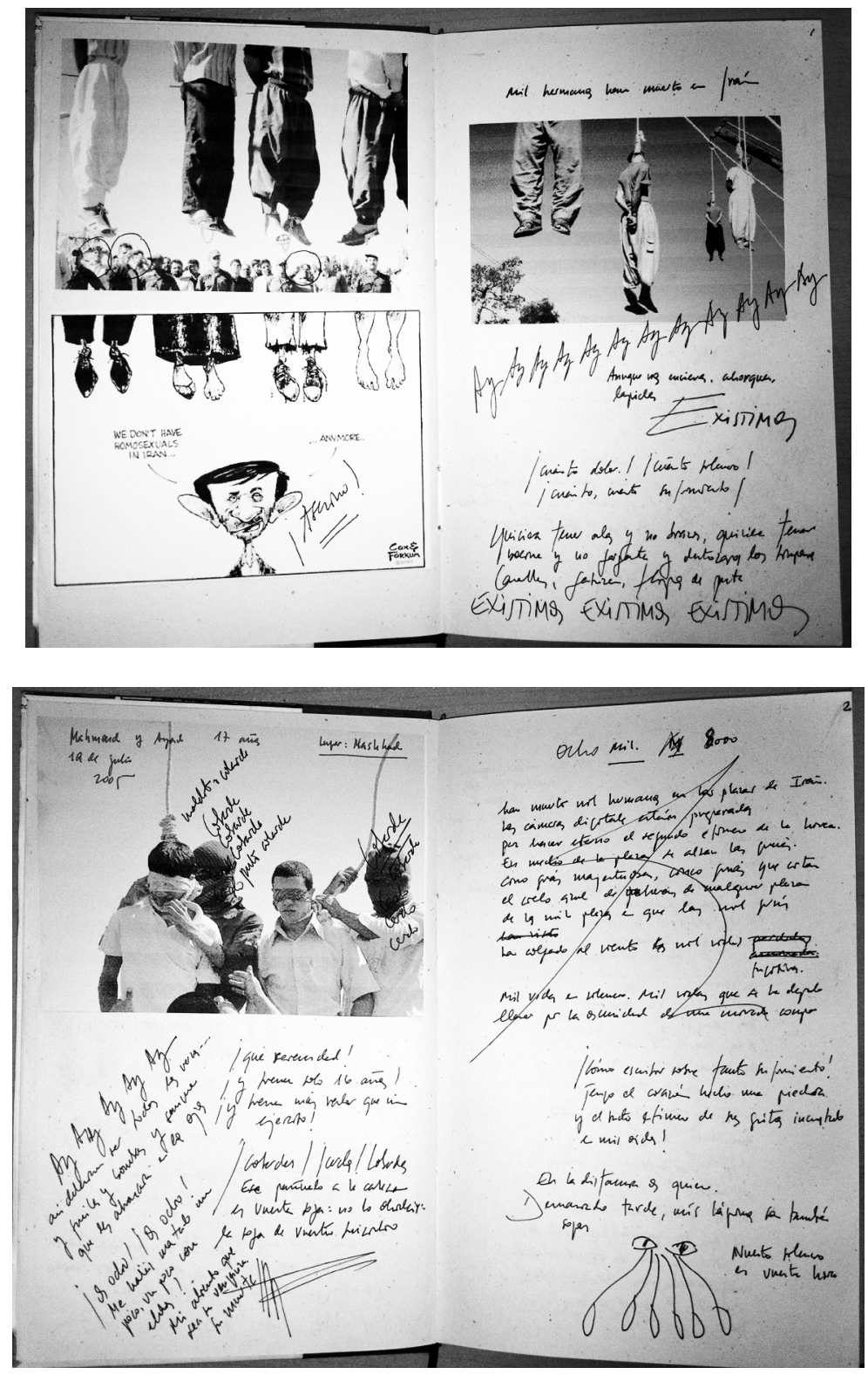

Pero además del dolor por el asesinato ("Ay, ay, ay, ay, ay... así deberían ser todos los versos, y fusiles, y bombas y sangre que les abrasaran los ojos"), de la rabia por su cobardía ("Cobardes, cerdos, cobardes Ese pańuelo a la cabeza es vuestra soga: no lo olvidéis, la soga de vuestro suicido"; "Quisiera tener alas y no brazos, quisiera tener bocina y no garganta, y destrozaros los tímpanos. Canalla. Gentuza, Hijos de puta”) y de 
la necesidad de escribir en mayúsculas EXISTIMOS ("aunque nos encierren, ahorquen, lapiden..."), lo cierto es que un tema comenzó desde el principio a convertirse en el eje de la obra, de esa obra que tenía necesidad de escribir: la denuncia de nuestro silencio. La denuncia de mi propio silencio, pues solo tres años después del asesinato fui capaz de abrir los ojos y de pararme ante el abismo de las imágenes: "En la distancia, os quiero. Demasiado tarde, mis lágrimas son también sogas. Nuestro silencio es vuestra horca".

En septiembre de 2007, el entonces presidente de Irán, Mahmud Ahmadineyad afirmó con orgullo en la Universidad de Columbia que "en Irán no tenemos homosexuales". La noticia que publicó Ángeles Espinosa en El País el 30 de septiembre de ese año con el título "Ser homosexual en el país de Ahmadineyad", me permitió conocer algo más de la realidad iraní:

"Entonces, ¿̇yo no existo?”, exclama incrédulo M., un gay acomodado de Teherán ante la afirmación de que "en Irán no tenemos homosexuales" pronunciada por el presidente, Mahmud Ahmadineyad, en la Universidad de Columbia el pasado lunes. "Lo que debiera hacer es informarse antes de hablar para no meter la pata como con el Holocausto", añade Taha, de los pocos gais iraníes que ha aceptado hablar con este diario. La discreción es la norma de supervivencia en un Estado cuyo código penal establece la pena de muerte para quien mantiene relaciones homosexuales. Algo que también ocurre en países aliados de EE UU como Pakistán, Arabia Saudí o Yemen. "Ahmadineyad solo tiene que darse una vuelta cualquier tarde-noche por el parque Daneshju para descubrir que en su país sí que hay homosexuales", sugiere un estudiante universitario. El Daneshju es uno de los típicos lugares de encuentro gay de Teherán. Quizá el más democrático. A diferencia del centro comercial Jam-e Jam, donde el ambiente pijo hace que sus camisetas ceñidas y sus cejas arregladas pasen desapercibidas, en el parque confluyen chicos tanto del norte rico como del sur más modesto. A menos que alguno se muestre extremadamente carińoso, la policía no suele intervenir ${ }^{1}$.

Y comencé a escribir. Un primer poema con el título de "Mil", que en una segunda versión pasó a ser 8000, seguramente influido por los gustos numéricos de Enrique Falcón y su La marcha de 150.000.000, que por aquel entonces — como ahora- me tenía fascinado. $\mathrm{Y}$ en esos días escribí el primero de los poemas, que no llegó nunca al texto impreso:

Han muerto mil hermanos en las plazas de Irán.

Las cámaras digitales están preparadas

para hacer eterno el segundo efímero de la horca.

En medio de la plaza se alzan las grúas.

Cinco grúas majestuosas, cinco grúas que cortan

el cielo azul de Teherán, de cualquier plaza,

1. https://elpais.com/diario/2007/09/30/internacional/1191103203_850215.html (consultado el 8 de enero de 2019). 
de las mil plazas en que las mil grúas

han colgado al viento mil vidas fugitivas.

Mil vidas en silencio. Mil vidas que se han dejado

llevar por la complicidad de una mirada cómpl....

Un poema que no pude terminar..., que quedó truncado en la última palabra: "¡Cómo escribir sobre tanto sufrimiento! Tengo el corazón hecho una piedra y el tacto efímero de sus gritos incrustado en mis oídos".

Pero comencé a escribir. Y comencé a buscar información en todos los medios posibles. Llegué al informe de Amnistía Internacional y, sobre todo, llegué al documental Etre gay en Iran, que emitió la cadena canadiense de noticias CBC en el año 2006. Gracias a este reportaje pude poner cara a los primeros activistas gais iraníes: a Arsham Parsi, que, gracias a Internet y los chats, comenzó a defender los derechos de gais, lesbianas y transexuales en Irán, primero con una lista de correo en 2001 (Rainbow Group) y luego, desde 2002, con una asociación: Palestinian Gay and Lesbian Organization, que en 2006 pasó a llamarse Iranian Queer Organization, con sede central en Canadá, donde tuvo que huir Arsham, así como el secretario de la misma, Mani Zahiar. En el reportaje de CBS News se pone espacio a los lugares de encuentro gais en Teherán: el centro comercial Jam-e Jam, o los parques Mehlat y Daneshju, así como los testimonios de Homan y de Shirin, una transexual que de sus padres solo escuchó una frase: "Ve a tu habitación y no salgas de allí nunca más". Al inicio del libro rescaté una frase que no dejaba de repetir Arsham Parsi en toda entrevista que le había escuchado o leído: "No nos dejéis solos".

En febrero de 2008 comenzaron los versos y las dudas. Por un lado, la duda del lenguaje, de la oportunidad del lenguaje poético para la finalidad que me había impuesto: la denuncia de los asesinatos de Mahmud y de Ayaz, como símbolo de la injusticia que nos rodea a lo largo y ancho de nuestra experiencia, de nuestra vida, y, sobre todo, la denuncia de nuestro silencio ante tantas injusticias, causa de que se sigan manteniendo en la actualidad. Dudas que dejé escritas en algunas de las páginas del cuaderno, a medida que iba escribiendo:

Los símbolos. Es el momento de los símbolos. Bien puede decirse que mi poesía se basa en las imágenes. En esa imagen poética que exploro, que me domina en el éxtasis creativo y que intento domar en la ridícula geografía de los versos. He intentado llevar las imágenes hasta los límites de las sílabas contadas, de versos medidos, pero no estoy seguro de que el resultado me satisfaga. O quizás no me vale la pena el esfuerzo. No sé. Pero ahora es otra cosa. Quiero, deseo, creo que es necesario abrirme a mi mundo, a este mundo injusto que me rodea. Pero me da pudor. Necesito gritar mi repugnancia por tanta barbarie, denunciar tanto dolor y tanta muerte, pero me parece que un verso resulta una expresión demasiado frívola. Pero no sé otra. No consigo domar otra expresión para contar lo que pienso, para pensar y reflexionar sobre lo que me hace sufrir. El verso como expresión me resulta inevitable. Pero no así la imagen... la imagen me resulta ahora superflua. Como intentar hacer del dolor ajeno un objeto 
objetivamente hermoso, interesante... ¡Solo de pensarlo me entran náuseas! Pero quizás el vehículo esté en el símbolo En ser capaz de trasladar esa realidad que me aterra, que necesita ser rescatada del silencio, que desconozco en su biografía para alzarlo a algo que nos supere, que nos ilumine. No sé. Quizás sea este el camino.

Y los versos seguían surgiendo a partir de nuevas imágenes, de nuevos datos. La denuncia tenía que llenarse de datos, de conocer un poco mejor el Teherán del que iba a hablar, de ese centro comercial Jam-e Jam, o del parque Daneshju, o de la sharía y de los 80 azotes que se impone de castigo por toda "relación impropia"...

Unos días después escribo lo siguiente, espejo de mis dudas, de mi necesidad de escribir, de seguir escribiendo, de denunciar, de seguir pretendiendo que la denuncia pudiera traspasar el verso para convertirse en voz, en grito, en alarido, en estruendo...

Sigo sin resolver el conflicto de este nuevo libro, de este dejar escrito en este cuaderno hecho a mano, con un bolígrafo última generación en mi cama, con la calefacción alta y el frío al otro lado de las buenas ventanas de mi casa, mi denuncia. Sigo sin resolver el conflicto de buscar estas imágenes, estos versos para denunciar, para escribir las tragedias de los otros, de otros que sufren en el silencio, en los gritos de su vida cotidiana. Es el conflicto entre la ética y la estética. El conflicto entre estas dos vertientes, estos dos abismos que ahora se abren ante el querer sumirme en este puzzle de angustias y de dolor que quiero hacer míos, para así convertirlos en poesía. En mi poesía. Dudo y esta duda me convierte en frío espectador, como si la duda fuera un velo, un extraordinario velo de distancias. Y dudo y esta duda me aleja de la creación por más que la herida esté abierta, y el dolor de ahí afuera, este dolor que sin ser mío lo es porque es de todos me sigue enloqueciendo. No puedo llorar. Es hora de ponerse a escribir. De dejar atrás las lamentaciones, las dudas, estos conflictos que, como tales, no dejan de ser igualmente absurdos.

Pero, sin darme cuenta, obsesionado con esta idea, de querer convertir el verso en un grito, en un arma efectiva y concreta, inmediata, no me di cuenta que estaba cayendo en una trampa, que bien puede ejemplificarse en este poema que nunca se llegó a publicar, el primero de los poemas escritos después de la reflexión anterior:

Si pudiera, yo también os enviaría al paredón de la vergüenza sin cerrar los ojos, sin dejarme arrastrar por las grietas de las dudas.

Si pudiera, también os marcaría las espaldas con el fuego lento de los azotes y de mi desprecio. Escupiría en cada uno de vuestros pasos y me reiría de cada uno de vuestros gestos, 
de los más cotidianos, de los más invisibles, de los que ensayáis delante de los espejos.

Y lo haría sin pestañear siquiera.

Y lo haría sin rebajar el sufrimiento,

el dolor de vuestras espaldas ensangrentadas

y vuestros labios indecisos y claustrofóbicos.

Si pudiera,

también os colgaría de la más alta de las grúas,

os dejaría allí hasta que los cuervos

de las habladurías, de los silencios

se cansaran de merodear por vuestra sombra.

Os ahorcaría sin ninguna duda,

y quizás también os haría fotografías,

inmortalizaría el segundo en que vuestro cuello cruje

y vuestro último suspiro se confunde entre los aplausos,

entre las indecentes voces, los gritos ansiosos

de todos los que nos agolpamos en la plaza.

Una plaza rosa.

La única plaza rosa, llena de volantes

y de la geografía imprecisa de los tacones.

Si pudiera,

si me dieran un segundo, una décima de segundo,

os escupiría a la cara toda mi rabia,

os reventaría los oídos con nuestros derechos

y dejaría hueca, como una campana,

vuestras leyes, esas que a vosotros

sí que nos permiten ahorcarnos,

sembrar de sangre nuestras espaldas

y hacer que nuestras miradas de deseo

se conviertan en muecas grotescas y enfermizas.

Si pudiera,

si tuvieran al menos por un segundo el poder,

no me temblaría la mano en exterminaros,

para completar en un segundo, en una décima,

lo que vosotros nos venís haciendo desde hace siglos.

La trampa del libelo. Este era el abismo al que, sin quererlo, al que mis dudas me llevaban a caer de manera irremediable. Y era todo lo contrario de lo que yo quería escribir. Y entonces, según veo por los apuntes, por las dudas y los pensamientos emborronados en los márgenes de los poemas escritos, me di cuenta de que el camino no era solo de- 
nunciar la barbarie del asesinato de los jóvenes Mahmud y Ayaz en el Irán de 2005, no era solo denunciar nuestro silencio ante esta y ante tantas y tantas injusticias que hoy - como ayer- se producen a nuestro alrededor, en nuestro mundo, por más que nos empeñemos en mirar hacia otro lado, en esconder la cabeza en las montañas de nuestros problemas personales, en estos problemas políticos creados en las inútiles campañas electorales. En realidad, había otro eje, otra línea maestra que debía explorar, que debía poner en primer plano: el amor. Contar el amor de Mahmud y Ayaz —ese amor que les dio la vida—, cantar historias de amor de una sola noche, volver al recuerdo de un amor que pudo ser pero que las circunstancias sociales y familiares no lo han hecho posible... tres líneas maestras con los que se iba tejiendo el libro, y un procedimiento, una búsqueda de una mezcla de lenguajes y de recursos. Si con mi primer libro de poemas Libro de horas (Calambur, 2000) había indagado imitar procedimientos narrativos en un libro poético, si el teatro se dejaba traslucir en Prometeo condenado (Calambur, 2003) o en Tríptico (Sial, 2009), ahora era el momento de experimentar con procedimientos propios del lenguaje periodístico. De ahí, que la historia de Mahmud y Ayaz, la denuncia de nuestro silencio ante las injusticias y el canto al amor se viera desde diferentes perspectivas, en unos poemas que se pudieran ir intercalando, buscando las voces protagonistas para que cada una pudiera dar su visión sobre este mismo tema, esta misma sensación y necesidad. De ahí que en las primeras versiones este libro tuviera el título de Puzzle.

Pero, ¿realmente funcionaba aquello que estaba escribiendo, que se había convertido en una obsesión desde que descubriera las fotografías en el ordenador?

En el mes de octubre de 2009, Miguel Losada me invitó a participar en el XVI ciclo de Los Viernes de la Cacharrería en el Ateneo de Madrid. La cita sería el 16 de octubre y, debido a unas obras en la sala de la Cacharrería, tuvimos la suerte de recitar en el Salón de Actos. ¿Qué mejor ocasión, qué mejor espacio y lugar para dar a conocer lo que llevaba escrito de Puzzle, de esas voces en el silencio que se habían ya concretado en seis? Así que le pedí a varios amigos actores, Álvaro Carvajal Fernández, Ernesto Filardi, Ana Garrido, Carmelo Hernando, Ana López de Castro y Diana Manrique que le pusieran cuerpo a esas voces al final del recital... Se daba la circunstancia que Ana Garrido, Diana Manrique y Ana López de Castro, del grupo Aldaba, habían estrenado el 7 de marzo de aquel mismo ańo la obra Del amor y sus sombras a partir de los poemas de Tríptico.

Y allí, en el Salón de Actos del Ateneo de Madrid bien se puede decir que se terminó el libro. Ahí estaba la prueba de que la apuesta de la mezcla del lenguaje poético con el periodístico funcionaba, que la mezcla de voces en el puzzle de las posibilidades alejaba el texto del libelo para convertirlo en una potente arma de denuncia. El silencio sonoro, las lágrimas que quemaban en las mejillas estaban por encima de cualquier palabra. Atrás quedaron las dudas. Atrás los peligros. Ahí estaba ya el libro preparado para ser terminado, para que las voces pudieran seguir gritando más allá del tiempo de la cotidianidad que todo lo consume, que todo lo olvida. 
En octubre de 2012 se publicó la primera edición de Y se llamaban Mahmud y Ayaz en la editorial Amargord, en la espléndida colección Transatlántica que dirige Edmundo Garrido. En la actualidad, va ya por la tercera edición ${ }^{2}$.

No hay mayor placer que recibir las primeras reseñas, las primeras críticas, que se destaque la finalidad con la que el libro había sido escrito. El 15 de enero de 2014, Juan Varela-Portas de Orduña inicia su reseña al libro en su blog "Náufragos en tiempos ágrafos", con las siguientes palabras: "Este es un libro de los que a mí me gustan, escrito con el cuchillo entre los dientes al tiempo que con 'el íntimo cuchillo en la garganta' (Borges), un libro que dice cosas y no solo palabras", por lo que no puede extrañar su conclusión: "José Manuel Lucía Megías ha escrito, así, un libro que, por un lado, nos hace sentir en nuestras propias carnes imaginarias el horror de la situación que vive quien no puede desarrollar su sexualidad y su amor, y por otro lado nos hace reflexionar sobre la construcción del 'yo' en sus relaciones entre los deseos y los brutales condicionamientos sociales. De este modo, Lucía Megías consigue hacer del íntimo cuchillo en la garganta un cuchillo de amor entre los dientes"3.

Y el mismo tino crítico encuentro en la reseña que Alberto García-Teresa publicó el La República Cultural en octubre de 2013:

La obra quiere ser una lucha contra el olvido, una reivindicación de la memoria. Por eso se insiste en recuperar sus nombres (desde el título) y su edad, repitiéndolos constantemente a lo largo de todo el volumen. [...] A su vez, el autor realiza una condena constante de nuestra complicidad al no denunciar estos hechos: "Fue necesario nuestro silencio", se reitera en varias piezas, donde el "nuestro" puede entenderse como una apelación a diversos colectivos sociales de distintos contextos. Y es que el poeta no duda en señalar que esa complicidad viene dada por intereses geopolíticos, que hacen que la economía prime sobre la defensa de los derechos humanos. De hecho, finalmente puede interpretarse la obra como una condena de la pena de muerte en general. En definitiva, se trata de un hermosísimo canto contra la homofobia; un doloroso homenaje a quienes deciden no silenciar su amor a pesar de las imposiciones ${ }^{4}$.

Valgan estos dos críticos, de los primeros y últimos que se han acercado a la obra para poder comprender la alegría de haber conseguido que Mahmud y Ayaz sigan estando vivos en nuestra conciencia, sean el grito necesario para que nos quedemos sin garganta

2. El texto se ha reproducido también en José Manuel Lucía Megías, El único silencio. Poesía reunida (19982017), Pigmalión, Madrid, 2017, pp. 389-412, y una selección en José Manuel Lucía Megías, Yo sé quien soy. Inventario de una noche (Antología poética), selección y prólogo de Pablo M. Moro Rodríguez, Sial/ Contrapunto, Madrid, 2018, pp. 147-170.

3. http://naufragosentiemposagrafos.blogspot.com/2013/01/y-se-llamaban-mahmud-y-ayaz.html (consultado el 9 de enero de 2019).

4. https://larepublicacultural.es/article7598 (consultado el 9 de enero de 2019). 
a la hora de denunciar tantas injusticas. Y ahora no me cabe duda de que sea la poesía el cauce adecuado para hacerlo.

"Los martes, milagro" comenzó su andadura en enero de 2013 en el Centro Cultural Fernán Gómez de Madrid. Es un proyecto de Arte Factor S. L., que han llevado a cabo Carlos Jiménez y José Claudio. Sin duda, es una de las apuestas culturales más sorprendentes y exitosas que se han vivido en la capital en los últimos ańos. "Los martes, milagro" tiene la finalidad de acercar la poesía a todos los públicos por medio del montaje de obras teatrales a partir de los textos de diferentes autores, en especial, acercándose a sus textos menos conocidos. Santa Teresa de Jesús, Cervantes, Vital Aza, Campoamor, Samaniego, Rosalía de Castro, Antonio Machado, Federico García Lorca, Pablo Neruda, Miguel Hernández, José Emilio Pacheco, Ángel González o Luis Alberto de Cuenca han sido poetas que han protagonizado algunas de estas sesiones. Y se llamaban Mahmudy Ayaz es el único que, como libro, se ha llevado a las tablas en este proyecto.

La primera versión de Voces en el silencio, mucho más apegada al texto original, con dirección y dramaturgia de Carlos Jiménez, iluminación de José Claudio e interpretada por Ana Turpín, José Bustos y José Troncoso, fue estrenada el 10 de junio de 2014. La sala llena. Había llegado el momento de la respiración compartida:

El pasado martes se ofreció en el Teatro Fernán Gómez una puesta en espacio del estremecedor poema de José Manuel Lucía Megías "Y se llamaban Mahmud y Ayaz", con los actores José Bustos, José Troncoso y Ana Turpín y dramaturgia de Carlos Jiménez. La gente de teatro recuerda nombres como El mirlo blanco, Caracol o Anfisto$r a$, donde pasaron cosas que se recuerdan un siglo después. Este pequeño acto fue, de momento, un paso más para que un gran poeta se acerque a la escritura teatral. Todos sabemos que de esa mezcla han salido cosas que nos han puesto la vida del revés. Estoy seguro de que esa tarde del Fernán Gómez será una piedra en el agua y seguirá dando ondas durante mucho tiempo. (José Ramón Fernández, autor teatral)

Desde la primera fila, me veo inmersa en inquietante escenario negro, escueto, con tan solo un mástil del que cuelga una soga de ahorcado, y la silueta negra de una bella mujer árabe vestida de abaya, que nos va a introducir en la historia de amor de Mahmud y Ayaz, dos jóvenes iraníes de 17 ańos cuyo único pecado fue amarse y por ello fueron ahorcados en 2005. La historia medieval del sultán y su criado se repite en nuestros días. Amor y muerte ante nuestra mirada hipócrita, que José Manuel Lucía denuncia desde su bella poesía, acertadamente transpuesta al escenario teatral. Una breve obra que sacude con fuerza nuestra más íntimas convicciones haciéndonos ver que todavía hoy vivimos presos del cinismo y de las conveniencias sin atrevernos a hacer frente a la barbarie. La obra logró transmitir su mensaje porque, tras grandes ovaciones dedicadas al sobrio espectáculo, los espectadores que llenábamos el aforo parecíamos incapaces de mirarnos a los ojos (Milagros del Corral, exdirectora de la BNE y escritora) 
Misión cumplida. Fuera las dudas. El milagro del teatro ha convertido en cuerpo la poesía. Una vez, más5.

Y la obra ha ido recorriendo estrenos y teatros. A partir de la experiencia de esta primera obra, Voces en el silencio cambió sustancialmente, con nuevos actos, con un tercio más de versos según la obra original. La denuncia tenía que estar presente junto al canto del amor, de este amor que es eterno por haberse convertido en literatura, por ser espejo de nuestros propios sentimientos. Y esta nueva versión fue estrenada en el mismo ciclo el 16 de diciembre de 2014, a cargo de los actores Elisa Marinas, Daniel Miguelánez y Víctor Manuel Coso. Versión que fue puesta de nuevo en las tablas del 16 al 19 de abril del 2015. En enero de 2016 se representó, por primera vez, en un espacio privado, el Teatro Biribó de Madrid, con el siguiente elenco: Alfonso Gómez, Elisa Marinas y Daniel Miguelánez, y con la participación de Luna Paredes como ayudante de dirección, y Carlos Jiménez, que sigue siendo el responsable de la dramaturgia y de la dirección. En enero de 2017, volvió a representarse en el Centro Cultural Fernán Gómez en Madrid. Junto a Daniel Migueláñez, le acompañaron Crismar López y Javier Prieto. Y la historia no acabará aquí, ni mucho menos. Tan solo ha comenzado.

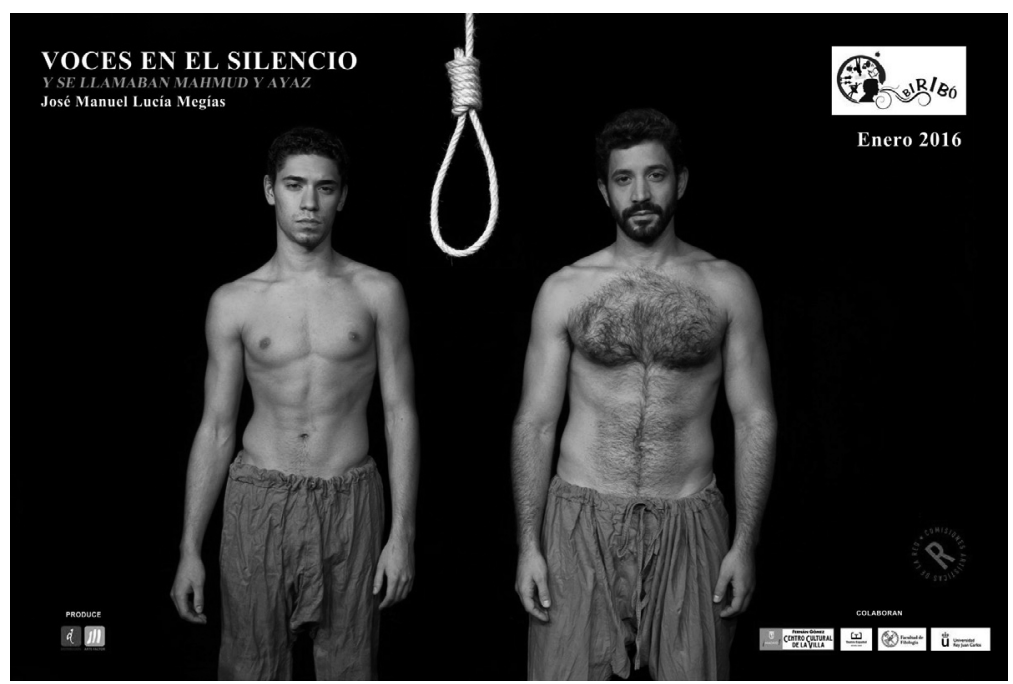

Muy largo me parece el camino desde aquel final del año 2008 a este del 2018, en que vuelvo a recordar el proceso creativo, la publicación y la transformación continua de un poema en una obra de teatro, renovada en cada representación, en cada puesta

5. Una versión actualizada de la dramaturgia ha sido publicada en José Manuel Lucía Megías y Carlos Jiménez, Voces en el silencio, Pigmalión, Madrid, 2016. 
de largo... Muy largo en experiencias y en sentimientos y sensaciones, y muy corto en voluntades y en denuncias que sigue siendo la misma.

Como autor, el proceso por el que he visto cómo mi libro de poemas $Y$ se llamaban Mahmud y Ayaz, con su estructura de mosaico de seis voces entrelazadas, se ha ido convirtiendo en Voces en el silencio, que es una obra de teatro, ha sido realmente apasionante. Las primeras lecturas de Carlos Jiménez para encontrar las voces adecuadas a las limitaciones teatrales impuestas por el formato del ciclo y de los momentos de crisis en que vivimos, los primeros textos y el ajuste para que la corporeidad de las voces de los actores pudieran sentirse cómodas en el espacio, las conversaciones sin final hablando de poesía, de teatro, de la vida y de la condición humana, han sido regalos que he podido disfrutar en primera persona en este complejo camino que va de los poemas a la obra teatral, para la que he escrito decenas y decenas de nuevos versos.

Este proceso me confirma, una vez más, la grandeza de la literatura: ser lugar de encuentro, de diálogo, de explosión de ideas y de sensaciones. Voces en el silencio solo podrá vivir, tener sentido cuando entras en una sala oscura para escucharla, o para sentarte en cualquier lugar para leerla.

Y se llamaban Mahmud y Ayaz.

Y tenían tan solo 17 años.

Y se siguen llamando Mahmud y Ayaz, y hoy los lanzan al vacío por el solo delito de creer que son diferentes, cuando sus verdugos son los únicos que son diferentes, los que merecen la más cruel de nuestras muertes, de nuestra atronadora denuncia y oposición a cada segundo, en cada momento.

Voces en el silencio, la versión ya depurada del libreto teatral después de varios estrenos, fue publicado en el año 2016 por la editorial Pigmalión, dentro de su colección "Candilejas", destinada a textos teatrales. El libro comenzaba con un prólogo de Luis Alberto de Cuenca, fechado el 2 de diciembre de 2015, que rescatamos en este momento, pues es testimonio de otro lector que conoció el proyecto de $Y$ se llamaban Mahmud y Ayaz desde sus comienzos y que disfrutó de varias de sus representaciones teatrales:

José Manuel Lucía Megías es uno de nuestros más destacados cervantistas. La iconografía del Quijote no tiene secretos para él. Ha escarbado como nadie en el apasionante territorio de los libros de caballerías, suelo nutricio de la inmortal novela de Cervantes. Ha comisariado importantes exposiciones en la Biblioteca Nacional de España. Es un estupendo filólogo, en toda la intención y extensión de esa palabra, hoy tan olvidada en los diseños curriculares universitarios. Pero además, y acaso sobre todo, José Manuel es poeta. Un poeta amoroso, si se me permite servirme del mejor adjetivo que define su producción lírica, pues es el amor, como en Petrarca, el hilo conductor de su cancionero poético. [...]

Una mujer ejerce como narradora, junto a dos hombres que después, por obra y arte de la magia escénica, se transformarán en los muchachos protagonistas. Toda 
la pieza, ahora publicada de manera ejemplar por Sial/Pigmalión, está transida de poesía, en un tipo de teatro lírico que me evoca aquella fiesta de la poesía dramática que Foxá publicó en 1940 y que lleva el exótico título de Cui-Ping-Sing, o los arrebatados dramas simbolistas de un Maeterlinck, en los que tanto he tenido el placer de bucear desde hace más de medio siglo. Y en esa poesía íntima que alimenta toda la obra no deja de estar presente, junto a la celebración amorosa, la denuncia de un caso real como el de los jóvenes amantes iraníes, a quienes la cruel ceguera de una sentencia injusta llevó al abismo de la muerte, cuando el único delito que cometieron en su breve existencia fue amarse con una devoción sin límites.

Se llamaban Mahmud y Ayaz. Sus nombres han quedado grabados para siempre en el catálogo de víctimas de las intransigencias y brutalidades que nutren la historia de los seres humanos a través de los siglos. Y se han convertido en exempla para todos, porque todos los que creemos en la libertad fuimos ahorcados con ellos por la barbarie fundamentalista, y todos tenemos la responsabilidad de poner nuestro grano de arena individual para que atrocidades como la que ellos padecieron no vuelvan a ocurrir en ningún lugar del planeta.

De ello nos habla Voces en el silencio, de José Manuel Lucía Megías. Voces que fueron silenciadas y que, pugnando por abrirse paso, se han ido convirtiendo en un clamor que pide libertad y que demanda igualdad ante la ley y respeto por la diferencia en la parte del mundo que niega esos derechos fundamentales.

Josep Maria Sala-Valldaura dedicó buena parte de su vida a la poesía y al teatro, a la enseñanza y a la investigación, a conocer el pasado teatral, y a no dejar de seguir creando un presente y un futuro poético. No puedo dejar de compartir, una vez más, parte de su pensamiento y su visión de la poesía (y de la literatura) en el siglo XXI, en este tiempo de silencios. La poesía solo puede sobrevivir en su espacio propio, en ese espacio de fronteras al que todos nos tenemos que acercar. Así lo escribió Sala-Valldaura en el 2002, palabras que siguen siendo esclarecedoras de nuestro presente, de la razón de nuestro futuro:

La nova era de la informació ha canviat el temps, l'espai, la velocitat, la percepció, la virtualitat... Aquesta nova etapa afavoreix un nou poder, i també unes noves tècniques, unes noves crítiques, unes noves metodologies, com ara la comparatística i els estudis culturals: un reconeixement de la importància de l'antropologia $i$, en general, de totes les ciències, val a dir, una importància de l'ésser humà i del saber (no tan sols el pur, l'experimental, l'especulatiu...). Pel que fa a la creació, si l'ésser humà està conquerint nous espais indeterminats, nous buits, nous silencis i cegueses, la poesia i la ciència n'estan contentes: continuaran així llur feina de frontera. La poesia, marginal i dissident, continuarà ampliant els marges i les dissidències, dient ara el que fins ara no deia ${ }^{6}$.

6. Josep M. Sala-Valldaura, "Per què els poetes en temps de penúria? (La poesia en l'era de la informació)", publicado en http://www.barcelonareview.com/31/c_jmsv.htm (consultado el 26 de diciembre de 2018). 